\title{
Structure and Geographical Distribution of the Intangible Cultural Heritage in Yunnan
}

\author{
Fei Zhang ${ }^{1, a}$, Nengxiu Cao ${ }^{2, b}$ \\ ${ }^{1}$ School of Tourism and Geography Science,Yunnan Normal University,Kunming 650500,China. \\ School of Education,Anhui Open University,Hefei 230022,China; \\ ${ }^{2}$ School of Educational Science and Management, Yunnan Normal University,Kunming \\ 650500, China \\ aemail:feizhang2003@163.com, bemail:yncnx2008@gmail.com
}

Keywords: intangible cultural heritage,type structure,geographical distribution

\begin{abstract}
Through analyzing their grade structure, type structure and spatial distribution with the method of spatial analysis technique of Arcgis, results show that:the grade structure is characterized by more provincial projects and fewer national projects, but a good number of provincial projects have the potential to be promoted to national ones. As to the characteristic of the type structure, traditional craftsmanship and folklore, folk dance takes up the majority followed by folk literature, folk music and traditional culture protection zones.The spatial distribution is centered by the southwestern Yunnan and the middle of Yunnan and the northwest Yunnan has more items than the scattered northeast and southeast Yunnan, which has certain relation with the major river networks in the province.
\end{abstract}

\section{Introduction}

Since the coming of the $21^{\text {st }}$ century, with the dramatically impact of globalization, urbanization and information, the advocate of culture diversity and the protection of human culture heritage have became an important issue and an urgent mission for many countries in the world. Under this background, the UNESCO (United Nations Educational Scientific and Culture Organization) published the Universal Declaration Cultural Diversity in its thirty-first session November 2001 General Conference, and then the thirty-second session 2003 General Conference passed Convention for the Safeguarding of the Intangible Cultural Heritage. The convention gave a accurate definition of intangible cultural heritage, that is “ The 'intangible cultural heritage' means the practices, representations, expressions, knowledge, skills-as well as the instruments, objects, artifacts and cultural spaces associated therewith-that communities, groups and, in some cases, individuals recognize as part of their cultural heritage...... The 'intangible cultural heritage' is manifested inter alias in the following domains: (a) oral traditions and expressions, including language as a vehicle of the intangible cultural heritage; (b) performing arts; (c) social practices, rituals and festive events; (d) knowledge and practices concerning nature and the universe; (e) traditional craftsmanship.”[1]

By June 2016, Yunnan province successfully declared the four batch of national intangible heritage lists, 110 approved, accounting for $8 \%$ of the total number of approved projects; successfully conducted on the declaration work of three bath of provincial intangible heritage lists, totally 427 approved, and local declaration work of the lists, made certain achievements. At present, the government of Yunnan province is carrying out the declaration work of the fourth batch of provincial intangible cultural heritage.

This study takes Yunnan province as the research area, taking the list of national and provincial intangible cultural heritage promulgated by Yunnan Province as the research object, the paper studied the type structure and spatial distribution of the intangible cultural heritage in this region by Arcgis software spatial analysis technology, then to analysis the formation of the geographical mechanism of this feature, to provide a reference for the protection and inheritance of the intangible cultural heritage and tourism development in Yunnan province. 


\section{Data and Methods}

The items data of national intangible cultural heritage lists in Yunnan province are mainly from the website of the government of People' s Republic of China (http://www.gov.cn), the website of the intangible culture heritage in China (http://www.ihchina.cn). The items data of provincial intangible heritage lists in Yunnan province are mainly from the website of protection of intangible cultural heritage in Yunnan (http://www.ynich.cn) and the website of the Yunnan province government (http://www.yn.gov.cn).

This study analyzed the level and type structure of intangible cultural heritage in Yunnan Province with data analysis tool of Microsoft Excel. The paper studied the type structure and spatial distribution of the intangible cultural heritage in this region by Arcgis software spatial analysis technology, then to analysis the formation of the geographical mechanism of this feature.

\section{Research process and result analysis}

\subsection{The Structural Characteristics of Different Level Intangible Cultural Heritage}

The State Council approved four batches of national intangible cultural heritage lists in 2006, 2008, 2011 and 2014 respectively. The government of Yunnan Province approved three batches of provincial intangible cultural heritage lists in 2006, 2009 and 2013 respectively. Department of Culture Yunnan Province government organized these regions and prefectures to declare the fourth batch of provincial intangible cultural heritage list in February 2016, which is expected to be released the fourth batch list of selected items by the end of the year. Statistically, there are 110 items in the fourth batch of national intangible cultural heritage in Yunnan Province, accounted for 20.5\% of the total; there are 427 items in the third batch of national intangible cultural heritage in Yunnan Province, accounted for $79.5 \%$ of the total, which is four times of national intangible cultural heritage items in quantity. Thus it can be seen, the items of provincial intangible cultural heritage in Yunnan Province is numerous of quantity and rich of resources, which provides rich resources guarantee for future promotion for the national intangible cultural heritage list.

Table 1 Quantity characteristics at different levels of intangible cultural heritage in Yunnan

\begin{tabular}{ccccccc}
\hline & Bacth I & Bacth II & BacthIII & BacthIV & Total & Proportion \\
\hline National level (item) & 34 & 38 & 21 & 17 & 110 & $20.5 \%$ \\
Provincial level (item) & 168 & 133 & 126 & - & 427 & $79.5 \%$ \\
Total (item) & 202 & 171 & 147 & 17 & 537 & $100 \%$ \\
\hline
\end{tabular}

\subsection{Type Structural Characteristics of Intangible Cultural Heritage}

Yunnan national and provincial intangible cultural heritages are rich and varied, which includes ten categories of the whole intangible cultural heritage items, and protection zone of traditional culture and village of folk traditional culture established by Yunnan Province, according to the provincial situation, totally 12 categories. According to its forms, the traditional crafts of Yunnan Province are the largest number of intangible cultural heritage items, totally 98 items, accounted for $18.2 \%$ of the total; secondly, the intangible cultural heritage items of folk customs are equal to the number of the traditional crafts in Yunnan Province, both 86 items, accounted for $16 \%$ of the total respectively; folk literature, folk music and protection zone of traditional culture are relative more items, accounted for 9.3\%, 8.8\% and 12.3\%; wrap up, traditional drama, traditional fine arts, traditional sports, traditional medicine and village of folk traditional culture are relatively less, accounted for 1.3\%, 4.5\%, 3.7\%, 2\%, 2.8\% and 5\% respectively (See Table 2 and Picture 1). Yunnan has 25 local ethnic minorities, the minority population are 15,640 thousand people (the year of 2015), accounted for $33.4 \%$ of the total province population, autonomous region covers $70.2 \%$ of the province area, which has the most local ethnic minorities, cross-border minorities, special minorities and ethnic autonomous regions in China.On the whole, the type Structural Characteristics of Intangible Cultural Heritage are mainly: taking traditional crafts and folk dance as the main items, taking folk literature, folk music and protection zone of traditional culture as the second place; taking wrap up, traditional drama, folk fine arts and traditional sports as the last place. 


\subsection{The Spatial Distribution Characteristics of Intangible Cultural Heritage}

\subsubsection{Distribution Characteristics of Administrative City}

Taking 16 cities and prefectures in Yunnan Province as the research scale of intangible cultural heritage. All of these cities and prefectures declared intangible cultural heritage items, but the distribution of type and quantity is not balanced. The items in Honghe, Chuxiong, Kunming and Dali are more concentrated, possessed 60, 58, 54 and 49 items respectively, accounted for 38\% of total; however, the items in Nujiang, Baoshan, Zhaotong and Qvjing are relative less, possessed no more than 30 items, and so far, the national items in Zhaotong city only have one, provincial items only have 15.

3.3.2 Distribution Characteristics Macro-Regional

According to the difference in location, geographical environment, economy and culture of each regions and prefectures, Yunnan Province was divided into 5 regions in space: middle of Dian, northeast of Dian, southeast of Dian, northwest of Dian and southwest of Dian. Thereinto, Kunming, Yvxi and Chuxiong is in middle of Dian, Qvjing and Zhaotong is in northeast of Dian, Honghe and Wenshan is in southeast of Dian, Dali, Lijiang, Nujiang and Diqing is in northwest of Dian, and Puer, Xishuangbanna, Baoshan, Dehong and Lincang is in southwest of Dian. From the point of view of spatial distribution, the most abundant of the intangible cultural heritage items are in southwest of Dian, totally 167 items, accounted for $29 \%$ of the total; the number of the intangible cultural heritage items in middle of Dian is 148 , accounted for $25.7 \%$ of the total, in the second place; the number of these items in northwest is 135 , accounted for $23.5 \%$ of the total, which is nearly equal to the number in middle of Dian; the number of these items in southeast is 94 , accounted for $16.3 \%$ of the total; the number of these items in northeast is only 31 , accounted for $5.4 \%$ of the total, the total number of these items in southwest, middle and northwest of Dian is accounted for $78.2 \%$ of the total, which is nearly four times as much as the total number in southeast and northeast of Dian. Generally speaking, the quantity distribution of intangible cultural heritage items in Yunnan province is mainly in the southwest and middle of Dian, these items are scattered in northeast and southeast of Dian.

\subsubsection{Watershed Distribution Characteristics}

Since ancient times, rivers are the cradles of human civilization. Most of the ancient residents choose the better natural conditions place of flat terrain, adequate water, agricultural to live, which is near to river, lakes and gradually forms the residents location or cities. The important carrier of the intangible cultural heritage is human beings, so the distribution is relevant with river.[2]The intangible cultural heritage in Yunnan also has the characteristics of the rivers distribution, besides, six rivers in the province are also scattered in the four plateau lakes, namely, middle of Dian lakes, west of Dian lakes, South of Dian lakes and east of Dian lakes[3], where is also the focus place of the intangible cultural heritage items. The intangible cultural heritage items in the southwest of Yunnan Province are mainly distributed in Langcang River, middle of Nujiang River and parts of Yiluowadi River; The intangible cultural heritage items in the middle of Yunnan Province are mainly distributed in Jinshajiang River, parts of Honghe River and middle of Dian lakes; The intangible cultural heritage items in the northwest of Yunnan Province are mainly distributed in Jinshajiang River, Langcang River, upper of Nujiang River and west of Dian lakes; The intangible cultural heritage items in the southeast of Yunnan Province are mainly distributed in Honghe River, Nanpanjiang (Zhujiang) River and south of Dian lakes; The intangible cultural heritage items in the northeast of Yunnan Province are mainly distributed in Jinshajiang River and east of Dian lakes.

\section{Conclusion}

Yunnan Province is a large province of variety cultural resources, but also the birthplace of ancient Dian Culture. There are a large number of ethnic cultural resources in the province, it is a treasury of the intangible cultural heritage. This has created very favorable conditions and a solid foundation for the development of intangible cultural heritage resources and the development of ethnic tourism in Yunnan Province, which is a rare mineral resources to expand the Yunnan tourism resources. This study mainly discussed the level structure characteristics, structural characteristics 
and spatial distribution characteristics of the intangible cultural heritage items in Yunnan Province, the formation mechanism of the rich and varied intangible cultural heritage items in Yunnan was analyzed from the two aspects of geographical conditions and cultural conditions, in order to rationally develop and utilize the tourism resources of the intangible cultural heritage in Yunnan Province.

\section{Acknowledgement}

In this paper, the research was sponsored by the National Social Science Fund of China (Project No.15XMZ41).

\section{References}

[1]UNESCO.Convention for the Safeguarding of the Intangible Cultural Heritage.http://portal.unesco.org/en/ev.php-URL_ID=17716\&URL_DO=DO_TOPIC\&URL_SECT ION=201.html.2003-10-17.

[2] Ruirui Li,Wei Zhao,Jing Chen.Structure and Distribution of the Intangible Cultural Heritage in Fujian.Areal Research and Development,2014 33 (6) 97-102

[3]Yiguan Yang.Comprehensive Physical Regionalization in Yunnan.Higher Education Press,Beijing,1991. 